\title{
THE ADMINISTRATIVE CONTROL OF TUBERCULOSIS.
}

\author{
By SIR R. THORNE THORNE, K.C.B., M.B., F.R.S., F.R.C.P.
}

\section{THE HARBEN LECTURES FOR 1898.}

I.

SIR RICHARD began by expressing his intention of passing over all social conditions, such as food, clothing, hours of labour, etc., which, though doubtless exerting a considerable infiuence on the greater or less prevalence of tubercular diseases in a community, did not come within the purview of the medical officer of health, and of limiting his treatment of the subject to such factors as were or should be matters for imperial or local legislation, and formed part of the official duties of health officers. There was abundant statistical evidence, at any rate since 1857 , when civil registration of deaths was instituted, of a general and progressive reduction in the mortality from all forms of tuberculosis, and at all ages, with one very important exception. Dr. Tatham had shown that this was not appreciably affected by more correct diagnosis or changes in nomenclature, and the mean death-rates for the decennia 1851-60, 1861-70, 1871-80, and the quinquennia 1881-85, 1886-90, and 1891-95, might therefore be safely compared. The mortality from all forms of tuberculosis per million living at all ages had fallen from 3,483 in the first to 2,122 in the last of these periods, a reduction of 36 per cent. The reduction in successive periods had increased from 28.6 to 44 per cent., and was most marked in the most productive age-periods of 15 to 35 , or early adult life, in which it had reached 52 per cent. The reduction in the phthisis rate for all ages had amounted to 45 per cent., but at the successive ages of $0-1,1-5,5-10,10-15,15-25$, $25-35,35-45$, and $45-55$, it had been $66 \cdot 0,60 \cdot 1,60 \cdot 0,57 \cdot 7,55 \cdot 2,45 \cdot 7$, $32-3$, and $29 \cdot 6$.

On the other hand, while the mortality from tabes mesenterica had been reduced by 8.5 per cent. at all ages, and 3 per cent. between those of one and ten, there had been an increase of 21.7 in the mortality among infants under one year.

The reduction in the mortality from all forms of tuberculosis had been mainly determined by that of phthisis as the predominant form, and this in its turn had resulted partly from the better social conditions already mentioned, and partly from the administrative measures of better sanitation and ventilation of houses and factories, the demolition of the slums that formerly disgraced our large towns, the opening up of wide streets, parks, etc., all of which were begun and their effects felt before the bacillary causation of the disease was known. The higher mortality from tuberculosis in back-to-back houses than in those with through ventilation in Salford had been well shown by Dr. Tatham. Although the sanitary conditions of the former were, on the whole, the better, the death-rate per 1,000 from tuberculosis was 5\%2, as against 2.3 in the latter. Dampness of sites and dwellings was another efficient cause, and, as Sir G. Buchanan long since showed, phthisis had almost always undergone a great reduction after the construction of sewers and drains had lowered the subsoil water. Paving, damp-proof courses, 


\section{Administrative Control of Tuberculosis [Public Health}

concrete foundations, etc., had a like effect. The influence of such sanitary improvements was felt especially among children whose lives were passed at home, and the explanation of the increase in tabes mesenterica side by side with a decrease in phthisis must be that, while the latter was the result of aërial infection and inhalation of the micro-organism, the former was due to its ingestion, the two possible vehicles of the bacillus being meat and milk. Both the Royal Commissions had reported that there was a certain degree of risk in the consumption of the flesh of tuberculous cattle, basing their conclusions on the results of experiments, in which portions of meat had been deeply impregnated with tuberculous matter, and tightly rolled up before cooking. But even under such exaggerated conditions the great majority of the animals escaped infection. The medical officers of health of the ports where the cattle trade centred had admitted that tuberculosis was far less frequent among foreign animals than among those bred in this country. Dr. Marsden, of Birkenhead, for instance, found among 60,000 animals inspected but sixty-eight tuberculous, of which only twenty-one had to be destroyed. These were practically wild cattle from prairies and ranches. Sir Richard Thorne had seen animals little better than skin and bone, but free from tuberculosis, the beasts being worn-out milch cows from poor farms, where they had been ill-fed and without shelter. Besides, the reduction of the mortality from all forms of tuberculosis had been most marked at the ages when the greatest amount of meat was eaten, and during a period in wbich the consumption of beef per head had increased to an enormous extent.

The condemnation of all animals irrespective of the degree of infection was therefore not to be entertained; but when several organs were affected the flesh should not be used. The only safeguard, however, was to be found in the total abolition of private slaughter-houses, and the substitution of municipal establishments with the appointment of trained inspectors, in the interests of the public health and the prevention of cruelty. In this direction continental countries were far ahead of us, and Scotland had already taken the lead here.

The principle of pecuniary compensation to the butcher for meat destroyed was condemned by four of the seven members of the Royal Commission on Tuberculosis on numerous grounds. The consequent loss was so small that many butchers refused to avail themselves of opportunities for mutual assurance; it was easily avoided; the animals were always milch cows that had yielded a profit to their owners for years, and were sold at a low price; freedom from the risk of loss incurred by such purchases would be demoralizing; and lastly, compensation, if allowed at all, should be drawn from local, not imperial, funds.

\section{II.}

The mean death-rate from tabes mesenterica among infants under one year of age had been per million living:

\begin{tabular}{lll|lll}
$1851-60$ & $\ldots \ldots \ldots$ & 3,160 & $1881-85$ & $\ldots \ldots \ldots$ & 4,356 \\
$1861-70$ & $\ldots \ldots \ldots$ & 3,800 & $1886-90$ & $\ldots \ldots \ldots$. & 4,462 \\
$1871-80$ & $\ldots \ldots \ldots$. & 4,467 & $1891-95$ & $\ldots \ldots \ldots$. & 4,046
\end{tabular}

or an increase of 28 per cent. in this last period. If to the deaths from this cause, about 7,000 in England and Wales, there were added those from tubercular meningitis, which originated in the same way, and was often but a secondary complication, there resulted a total 
of over 10,000 deaths per annum from one cause entirely preventible by means within the power of everyone. There was also a close relation between tabes mesenterica and infantile diarrhoea, and the death-rates from each rose and fell together. Probably many cases under each head should properly be returned under the other. Apart from errors of registration, which were probably mutually corrective, diarrhoea, or those catarrhal conditions of the alimentary canal to which infants were so liable, rendered them extremely susceptible of tubercular infection, which the less sensitive and, for the most part, healthy mucous membrane of the adult was able to resist.

Catble, and especially milch cows, were far more liable to tubercular diseases than man, and the conditions under which they lived, exhausted by milking for ten months in the year, highly fed with a view of combating the tendency to emaciation, and often crowded together in ill-ventilated sheds, increased their susceptibility, and rendered the infection of previously healthy animals almost inevitable. Experts gave the percentage of tuberculous cows, as diagnosed by post-mortem inspection, at from 20 to 40 , and by the tuberculin test at double this proportion. As a rule it was only when the udder was implicated that the bacilli were present in milk. This was demonstrated by Dr. Sidney Martin in the case of five out of fifteen tuberculous cows. The milk of the five cows induced tuberculosis in all the animals to which it was administered, though that of the others did not.

The detection of mammary tubercle by physical examination was very difficult, and even if it could be excluded at any given time, its extension from other organs might occur at any moment, while milk constituted the very best culture medium for the bacilli.

There were three procedures by which the danger of infection through milk must be averted :

1. The exclusion from dairy farms of all tuberculous animals, i.e, of all that reacted to the tuberculin test. This, however, would involve the immediate withdrawal of between 500,000 and 800,000 cows, many of them yielding healthy milk.

2. Strict and effective control by the officers of the county and municipal councils of all farms and dairies within their jurisdictions. No adequate means existed at present for this purpose. The regulations issued by many authorities were not enforced, and by some the question of cubic space was ignored. The Local Government Board had no power beyond refusing its sanction to such as it deemed too stringent! The Royal Commissioners of 1896 had proposed a set of rules, among which was the requirement of 600 to 800 cubic feet, with not less than 50 square feet of floor surface, for each cow, together with ample light and ventilation, to which end the other requirements were a means.

(Objectionable as cow-sheds in towns were on many grounds, the sanitary conditions of many in the country districts were often far worse as regards cleanliness and ventilation. Examinations of the cattle in rural and urban dairies in Lancashire, Liverpool, Manchester, etc., had shown that the percentages of tuberculous animals varied in the former from 18 to 28 , and in the latter from 3 to 6 only.

The practice of ranging the cows with their noses close against the wall was calculated to favour infection, mostly conveyed by the mucous discharges, and a space or walk of from 4 to 6 feet ought to be left between the mangers and the walls of the sheds.)

3. The systematic inspection of all sheds and cows, and of milk at railway-stations by competent veterinary surgeons, chemists, and 


\section{Administrative Control of Tuberculosis}

bacteriologists. Sanitary authorities should have power to inspect dairy-farms outside of their own districts sending milk to be sold within those districts.

No milk from cows showing clinical evidence of taberculosis should be allowed to be sold, and all cases of disease, of whatever kind, should be notified. This would involve powers of seizure and a right to compensation. But while the principle of compensation for meat intended for sale and seized as unsound was wrong, the case of milch cows was different. Only animals showing clinical signs should be seized, such seizure to be followed by slaughter, with compensation to the value of the carcass as such, if deemed fit for food; but if the seizure were found to have been uncalled-for, then to the full value of the cow as a milk-producer.

Then there was the prevention of the infection of healthy cows from the affected by eliminating the unhealthy from the herd and preventing the introduction of infected beasts. Further, no person suffering from phthisis should be allowed in eontact with cows or milk, and such cases would have to be notified and treated as "dangerous infectious diseases" so far as regards the actual sufferer.

Lastly, everyone had it in his power to absolutely exclude all danger of infection, tubercular or other, by the simple expedient of boiling the milk for a minute. If the taste of boiled milk were objectionable, the same result could be obtained by heating it for five minutes or so at a temperature of $170^{\circ} \mathrm{F}$. in a clean tin saucepan within another containing water. The popular prejudice against boiled milk was confined to this country, and under the circumstances was inexplicable.

\section{III.}

There remained to be considered the question of the practicability of exercising any control over persons suffering from pulmonary tuberculosis, or phthisis, the most communicable form of the disease, and one which carried off every year at least 40,000 persons in England and Wales, the majority of whom were in the best years of early adult life. While appreciating the motives which had inspired those who, in the interest of the public health, had urged the desirability of such measures, and the sanitary authorities who had applied to the Local Government Board for powers to include tuberculosis among the notifiable diseases, Sir Richard Thorne expressed his entire agreement with the final decision of the Board (although, owing to absence, he had taken no part in the antecedent deliberations), that it would be impracticable, and tend in its results to defeat the end in view. The clauses relating to the notification of infectious diseases applied to acute specific fevers of short duration, which rendered the patient physically incapable of attending to his affairs, and during which he was, for the time, already under strict control. These diseases were communicable in a high degree and in many ways, but rendered the patient a source of danger to others for a limited period only. In phthisis, not only were these conditions absent, but the patient's position was absolutely the reverse. The disease lasted for years. During the greater part of its course the patient was capable of working for the support of himself and his family, and the only means of communication lay in the sputa, to the disposal of which alone restrictions need be applied. When local authorities applying for special powers had been asked by the Local Government Board what measures they proposed to take on receiving notification of a case of phthisis, some had given no reply, some had mentioned dis- 
infection of rooms, etc., after the patient's death, for which the registration of the cause as at present would suffice; and others had proposed visitation of the house and the inculcation of the necessary precautions in co-operation with the medical attendant. A little reflection would show the impracticability of carrying out such a course of repeated visitation of hundreds or thousands of houses in large sanitary districts, where already it was found impossible for the medical officer of health to visit all the cases now notified. And if the patients were visited, there were no means of insuring the carrying out of the recommendations. An attempt in this direction had been made in New York within the last year, every physician seeing a case for the first time being required to notify it, as were the officers of all public institutions, hospitals, and dispensaries, and to see to the carrying out of numerous precautionary measures. But the numerous saving clauses deprived the law of all force, except as regards the very poor, and of all value save as a source of statistical information. In 1889 a crusade, as it was called, for the education of the public in respect of tuberculosis, by means of lectures, leaflets, house-to-house visitation, etc., had been undertaken with good results; but in New York, as in this country, the progress of ordinary sanitary improvement had already effected a great reduction in the mortality from phthisis before the educational movement began, and it was as yet too soon to judge of the results of the notification.

It was not desirable that persons suffering from phthisis should occupy the same rooms as the healthy, but the notification of such cases in houses of business would be followed by dismissal. If the young man or woman obtained another situation, it was not likely that he or she would, by consulting a medical man, court a repetition of the loss of the means of living. Phthisis, in its early stages, was very amenable to treatment, and often curable, provided the patient could enjoy good living and freedom from anxiety; but the consequences of notification would be the concealment and neglect of the disease, or the loss of all these circumstances nost favourable to successful treatment. On these and other grounds, as that the notification of phthisis, unlike that of fevers, would be the divulgence of professional secrets, a committee, appointed by the Academy of Medicine of Paris, had condemned in toto any such proposals, and their report had been confirmed by the Academy. Sir W. Broadbent had expressed himself very decidedly on the subject, maintaining that the question resolved itself into that of the disposal of the sputa, and asking what the sanitary authority would do with the patient when notified. The Academy admitted that reform was called for, but was of opinion that it rested with the medical attendant, who alone could see that the requisite precautions were observed; and alread̄y medical practitioners and health officers were working together to this end, theugh much more might be effected by the diffusion of information, e.g., the distribution of leaflets by the medical officers of hospitals, as was already done at Brompton; and by teachers, district visitors, and all whose work brought them in friendly intercourse with the poor in their own homes. The extension of sanatoria for the treatment of cases in their earlier stages was much to be desired, and a residence in these institutions would be in itself an education. If all persons could be brought to feel that the use of spittoons, or Japanese paper handkerchiefs, to be immediately burnt, was a duty they owed to their families, to say nothing of others, more good would be effected than could ever be achieved by legislative enactments. 